\title{
PENGENALAN TEKNOLOGI PENGONTROL BERBASIS ARDUINO DI SMK NEGERI 6 TANGERANG SELATAN
}

\author{
Samsurizal $^{* 1}$, Rizki Pratama Putera ${ }^{* 2}$, Miftahul Fikri* ${ }^{* 3}$, Dhami Johar D ${ }^{* 4}$, Dewi Purnamasari*5 \\ Wahyudi Sarimun ${ }^{* 6}$ Agung Untoro*7 \\ STT-PLN; Menara PLN J1. Lingkar Luar Barat Duri Kosambi, Cengkareng-Jakarta Barat \\ Program Studi Teknik Elektro, Fakultas Teknik \\ e-mail: 1 samsurizal@sttpln.ac.id
}

\begin{abstract}
Abstrak
Sekolah Menengah Kejuruan (SMK) merupakan salah satu lembaga pendidikan formal yang mempunyai tujuan menciptakan lulusan sesuai dengan standar kompetensi. Lulusan tersebut adalah lulusan yang siap menjadi tenaga kerja tingkat menengah yang terampil, terlatih dan terdidik, serta mempunyai sikap sebagai juru teknik dalam melaksanakan pembangunan dibidang teknologi. Keberhasilan SMK dalam menghasilkan lulusan yang mempunyai keahlian tersebut, dipengaruhi oleh mutu pendidikan. Salah satu upaya yang dilakukan agar lulusan SMK dapat bersaing di dunia kerja adalah dengan memberikan lebih banyak praktek dibandingkan teori. Salah satu materi yang diberikan di SMK adalah materi Sistem Mikroprosesor dan Mikrokontroler. Dari pelaksanaan program Kemitraan Masyarakat yang disenggarakan di SMKN 6 Tangerang selatan ini adalah meningkatnya pengetahuan dan pemahaman guru dan siswa-siswi SMK Negeri 6 Tangerang Selatan tentang Sistem Pengontrolan elektronis berbasis Mikrokontroler. Keinginan siswa untuk mempelajari sistem otomatisasi pengontrolan elektronis berbasis mikrokontroller. Pelatihan atau kegiatan ini sangat perlu untuk dikembangkan agar kegiatan berikutnya menjadi lebih baik dan berguna didalam peningkatan sumber daya manusia.
\end{abstract}

\section{Kata Kunci : Pengenalan Teknologi, Mikrokontroller, Arduino}

\begin{abstract}
Vocational High School (SMK) is one of the formal education institutions that has the goal of creating graduates in accordance with competency standards. These graduates are graduates who are ready to become middle-level workers who are skilled, trained and educated, and have the attitude as an engineering interpreter in carrying out development in the field of technology. The success of Vocational Schools in producing graduates who have these skills is influenced by the quality of education. One of the efforts made so that vocational graduates can compete in the world of work is by giving more practice than theory. One of the material given at the Vocational School is the Microprocessor and Microcontroller system. From the implementation of the Community Partnership program held at SMK 6 in South Tangerang this is an increase in the knowledge and understanding of teachers and students of SMK Negeri 6 Tangerang Selatan about Microcontrollerbased electronic control systems. The desire of students to study microcontroller-based electronic control automation systems. This training or activity is very necessary to be developed so that the next activity will be better and useful in improving human resources.
\end{abstract}

Keywords: Introduction to Technology, Microcontroller, Arduino 


\section{PENDAHULUAN}

Perkembangan teknologi yang pesat adalah salah satu akibat dari usaha manusia untuk meningkatkan kemudahan dan kenyamanan dalam memenuhi kebutuhannya. Peralatan elektronik hampir tidak dapat lepas dari kehidupan, dari yang sederhana sampai dengan yang canggih. Dalam menghadapi perkembangan teknologi yang semakin pesat dibutuhkan Sumber Daya Manusia (SDM) yang mampu bersaing dan memiliki kemampuan serta keahlian yang kompetitif. Salah satu usaha untuk meningkatkan kualitas SDM Indonesia dilakukan dengan mendorong dan menumbuhkan minat belajar masyarakat. Salah satu bentuk nyata yang dilakukan adalah melalui pendidikan dan pelatihan yang sesuai dengan standar kompetensi yang berlaku.

Sekolah Menengah Kejuruan (SMK) merupakan salah satu lembaga pendidikan formal yang mempunyai tujuan menciptakan lulusan sesuai dengan standar kompetensi. Lulusan tersebut adalah lulusan yang siap menjadi tenaga kerja tingkat menengah yang terampil, terlatih dan terdidik, serta mempunyai sikap sebagai juru teknik dalam melaksanakan pembangunan dibidang teknologi. Keberhasilan SMK dalam menghasilkan lulusan yang mempunyai keahlian tersebut, dipengaruhi oleh mutu pendidikan. Salah satu upaya yang dilakukan agar lulusan SMK dapat bersaing di dunia kerja adalah dengan memberikan lebih banyak praktek dibandingkan teori. (Damiri, 2012).

Salah satu materi yang diberikan di SMK adalah materi Sistem Mikroprosesor dan Mikrokontroler. Materi tersebut sangat penting untuk dipelajari, karena saat ini sistem berbasis sistem mikroprosesor dan mikrokontroler menjadi teknologi yang diminati dan berkembang di masyarakat. Bermula dari penerapan rangkaian elektronika analog, kemudian digital dan kini hampir semua peralatan menggunakan sistem mikroprosesor, misalnya: perangkat yang dekat dengan kita, seperti handphone, televisi, mesin cuci sampai ke instrumen ruang angkasa.

Salah satu jenis miktrokroler adalah Arduino, yaitu physical computing atau singleboard microcontroller yang bersifat open source. Arduino dirancang untuk memudahkan penggunaan elektromekanik dalam berbagai kegiatan. Microcontroller yang digunakan pada Arduino berjenis atmel AVR dengan berbagai jenis lainnya. Software Arduino dapat dijalankan pada sistem operasi Windows, Macintosh OSx dan Linux. (Abdul Kadir, 2013)

Arduino adalah sebuah produk design system minimum mikrokontroler yang di buka secara bebas (Alan G. Smith, 2011). Arduino menggunakan bahasa pemrograman C yang telah dimodifikasi dan sudah ditanamkan programmer bootloader yang berfungsi untuk menyembatani antara software compiler arduino dengan mikrokontroler. (W.Durfee,2011)

\section{METODE}

Alur kerja pelaksanaan PKM dapat dilihat pada bagan di bawah ini : 


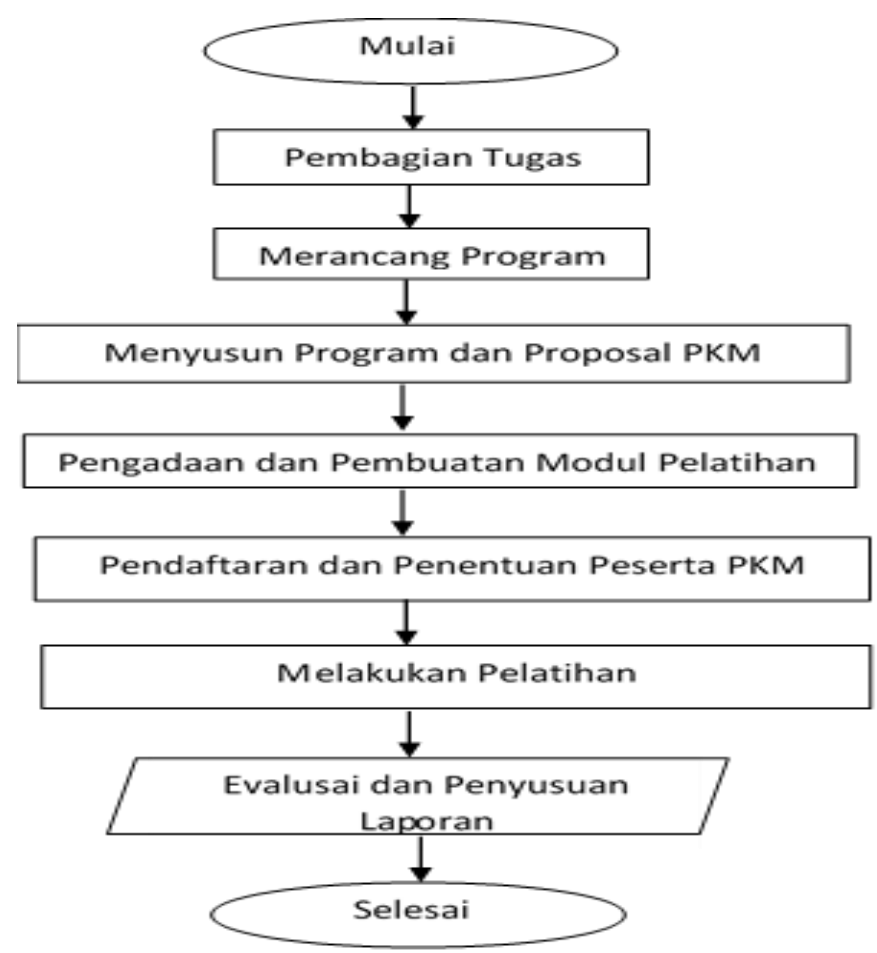

Gambar 1. Diagram alir PKM

\section{A. Sifat dan bentuk Kegiatan}

Pelatihan pengenal teknologi pengontrolan berbasis Arduino ini dilakukan dalam satu sesi diikuti oleh lebih kurang 60 peserta. Kegiatan ini dapat dilaksanakan dalam jangka waktu 2 hari kerja. Setiap peserta akan diberikan materi berupa pengetahuan, keterampilan,dan tes secara mandiri.

- Langkah 1:

Peserta pelatihan diberikan penjelasan mengenai teknologi pengontrolan, serta jenisjenisnya,

- Langkah 2:

Setelah mendapatkan penjelasan mengenai teknologi pengontrol Berbasis Arduino setiap peserta diminta untuk mempraktikan secara langsung

- Langkah 3:

Setiap peserta secara berkelompok akan di berikan soal-soal terkait dasar-dasar Arduino

- Langkah 4:

Evaluasi juga dilakukan dengan menggunakan pendekatan membagi pengetahuan (sharing) kepada peserta yang mengikuti sosialisasi ini. Cara Kerja berbagi ilmu pengetahuan tentang teknologi arduino ini adalah memberikan presentasi dan diskusi langsung ke peserta. Evaluasi dilakukan ke peserta di awal dan di akhir kegiatan sosialisasi. Evaluasi dilakukan secara langsung atau praktek. 


\section{HASIL DAN PEMBAHASAN}

\section{A. Hasil Kegiatan}

Kegiatan kemitraan masyarakat dengan tema Pengenalan Teknologi Pengontrolan Berbasis Arduino di SMK N 6 Tangerang Selatan diberikan secara gratis kepada siswa-siswi kelas XII selama 2 hari. Kegiatan tersebut dibagi menjadi dua tahap yaitu tahap pertama dimulai dengan pengenalan teknologi tersebut dan tahap kedua dengan mensimulasikan alat yang menggunakan teknologi Arduino, selanjutnya siswa mempraktekkan penggunaan teknologi arduino tersebut, serta problem solving dengan menggunakan sofware dan kit Arduino.

Kegiatan kemitraan pada masyarakat telah berhasil dilaksanakan pada tanggal $26-27$ Juli 2018 di SMK N 6 Tangerang Selatan. Kegiatan ini berupa pengenal serta pelatihan yang dimulai pada pukul 09.00 WIB sampai 15.00 WIB dengan waktu istrahat 1 jam. Peserta kegiatan ini merupakan siswa/i kelas XII sebanyak 2 kelas dengan jumlah total pada hari pertama 67 peserta dan pada hari kedua 71 peserta, kegiatan ini juga didampingi oleh Guru pendamping.

Pada hari pertama kegiatan diisi dengan pengenalan dasar tentang teknologi pengontrolan berbasis arduino, dimana pada sesi tersebut siswa/i dijelaskan teori tentang teknologi tersebut. Kegiatan diawali dengan berdoa dilanjutkan dengan menyanyikan lagu Indonesia Raya, kemudian kegiatan berjalan sesuai dengan jadwal kegiatan yang sudah disusun.

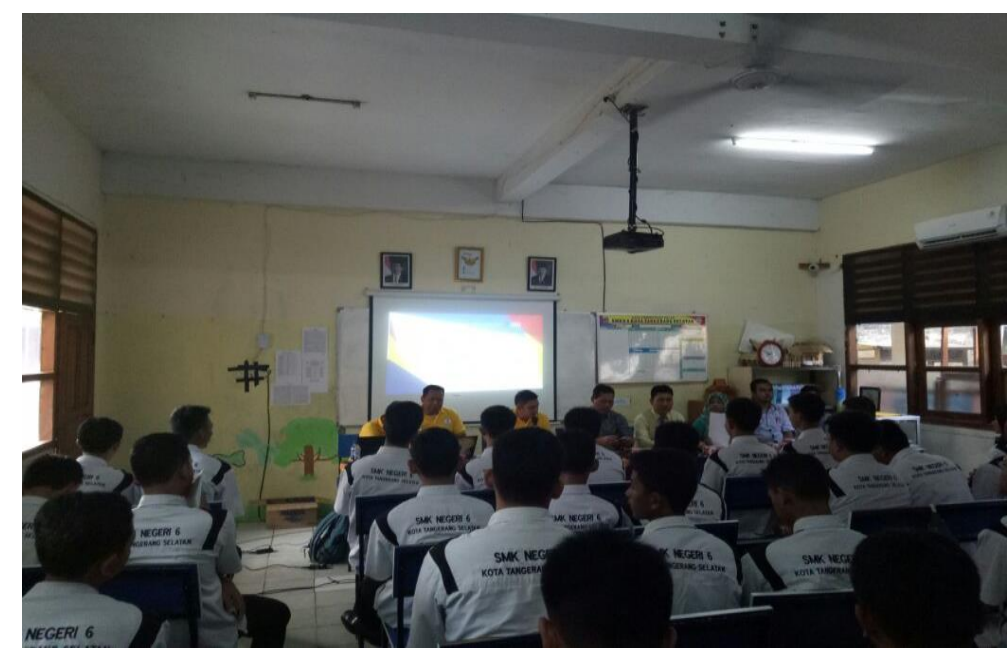

Gambar 2. Pembukaan Kegiatan PKM 


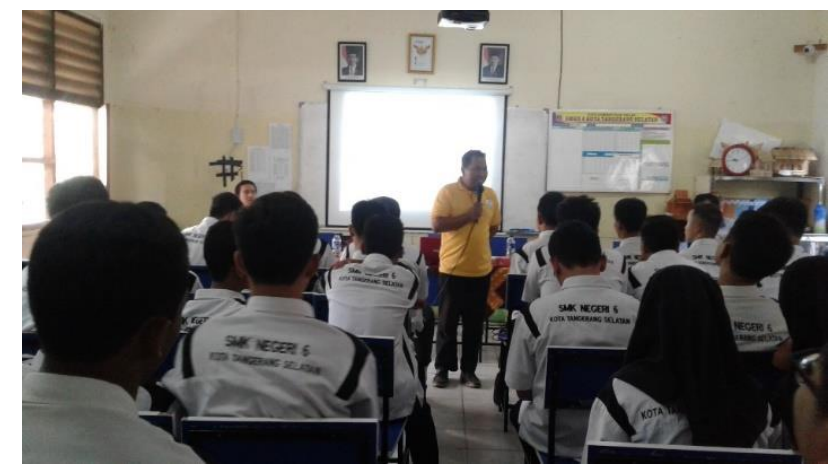

Gambar 3. Peserta Memperhatikan Penjelasan Mengenai Teknologi Arduino

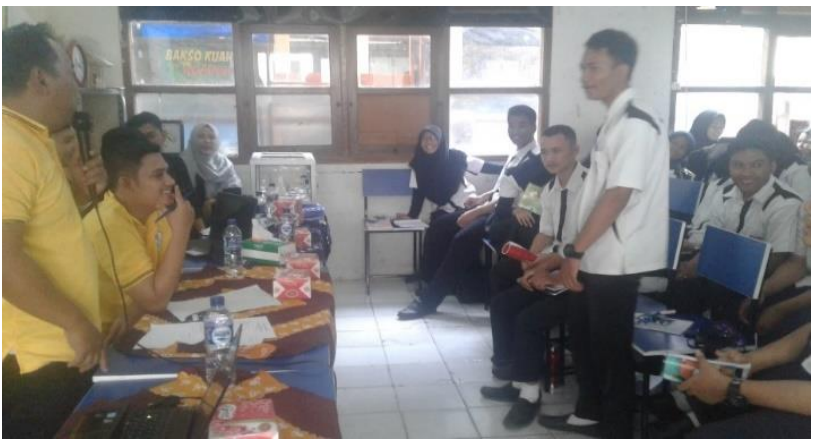

Gambar 4. Siswa Bertanya Tentang Aplikasi Teknologi Arduino

Masih dihari yang sama selanjutnya siswa/i dijelaskan software yang digunakan serta diajarkan bagaimana cara menginstal serta penerapannya. Pada sesi ini siswa sangat antusias dan serius dalam mendengarkan materi yang disampaikan oleh pemateri.

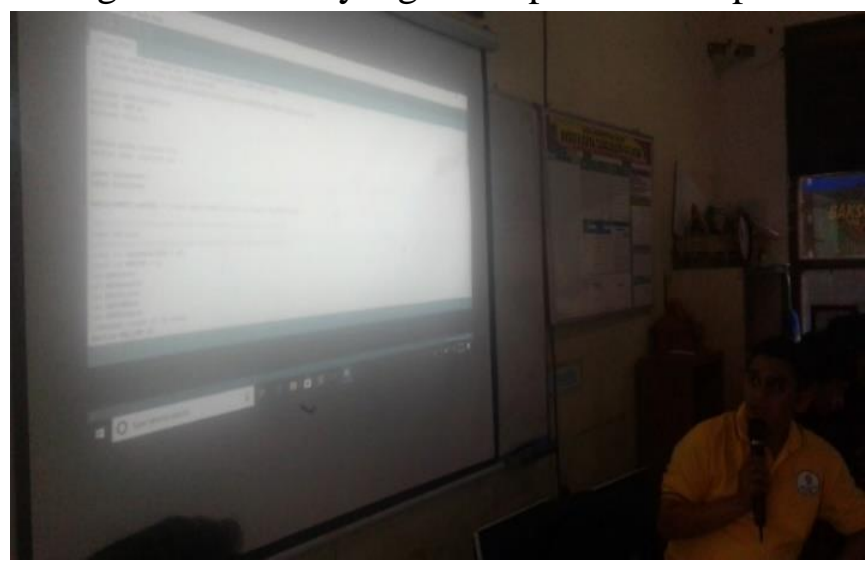

Gambar 5. Dijelaskan Software Yang digunakan 


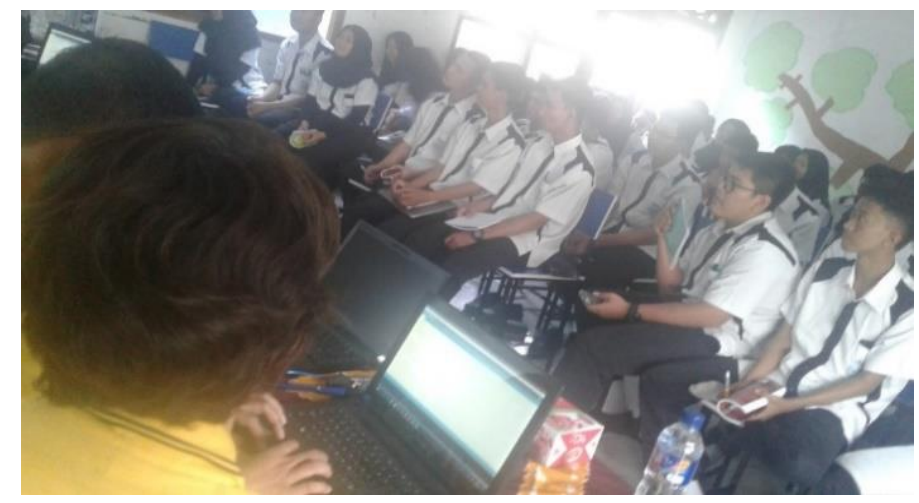

Gambar 6. Siswa Serius Mendengarkan Materi Yang di Sampaikan

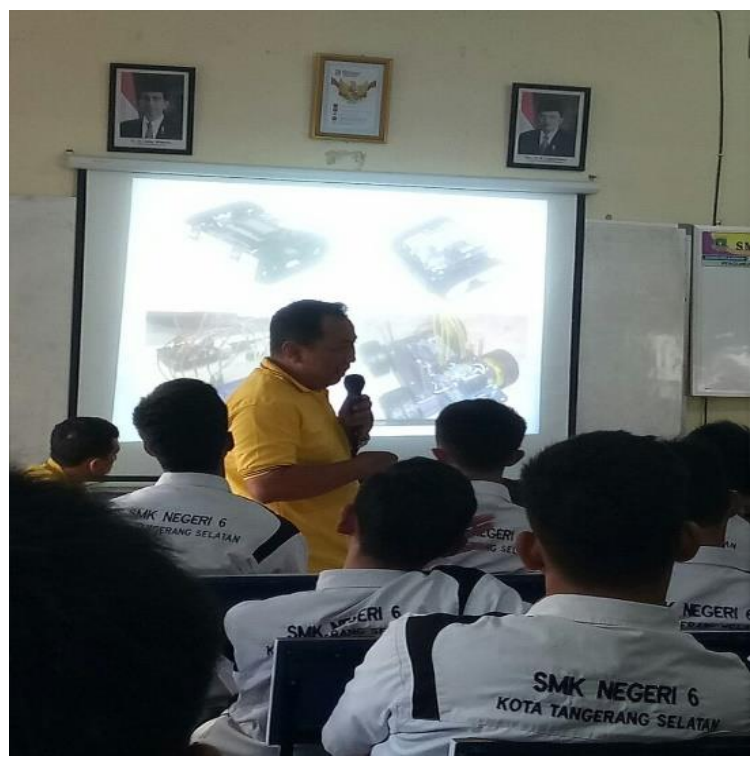

Gambar 7. Pemaparan Penerapan Teknologi Arduino

Pada hari kedua kegiatan dimulai dengan mendemokan alat yang menggunakan teknologi pengontrolan menggunakan arduino, dalam sesi ini mahasiswa sebagai pendamping di tugaskan untuk mendemokan alat dengan teknologi pengontrolan berbasis arduino. Peserta juga diperkanankan untuk bertanya tentang serta mencoba alat tersebut.

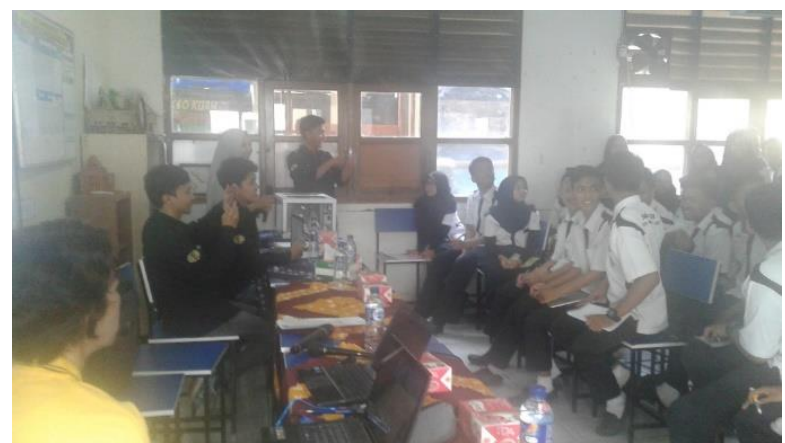

Gambar 8. Demo Alat Dengan Teknologi Pengontrolan Berbasis Arduino 


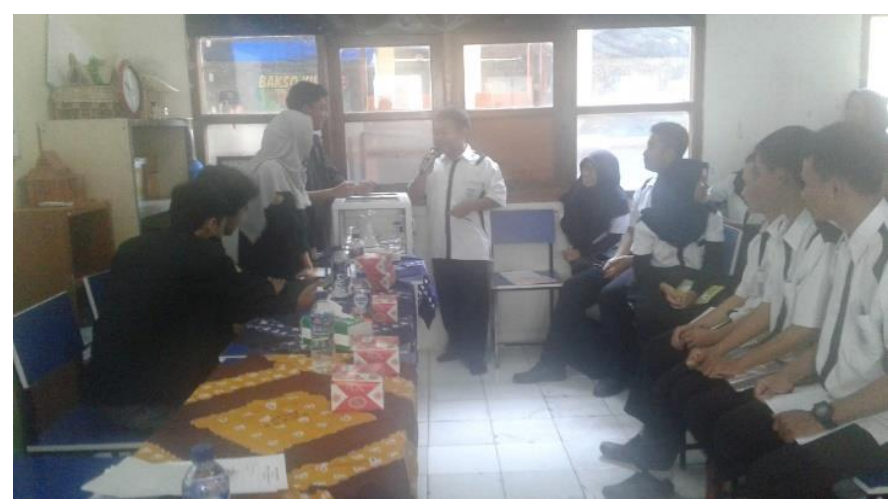

Gambar 9. Siswa Mencoba Alat Dengan Teknologi Pengontrolan Berbasis Arduino

Selanjutnya setelah mendemonstrasikan alat dengan teknologi pengontrolan berbasis arduino, peserta mencoba menginstal software dilanjutkan dengan mempraktekkan juga merancang penerapan teknologi arduino. Pada sesi ini peserta diminta membuat program dan merancang lampu yang mampu hidup secara bergantian. Peserta yang sudah selesai diminta untuk mempresentasikan hasil yang telah dibuat.

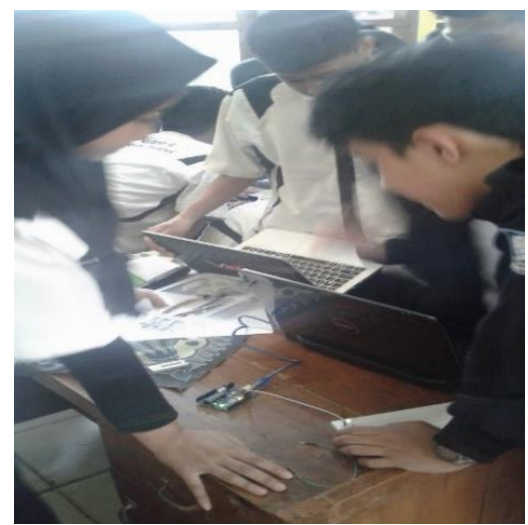

Gambar 10. Siswa Menginstal dan Menggunakan Arduino

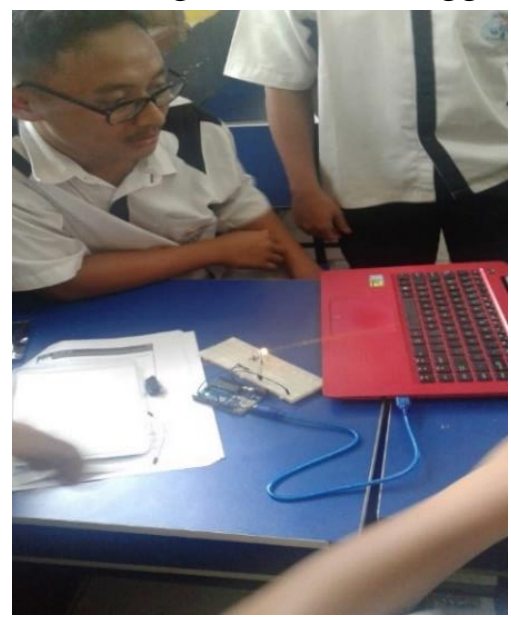

Gambar 11. Siswa Membuat dan Merancang Alat Menggunakan Arduino 
Kegiatan PKM diakhiri dengan penutupan dan penyerahan kenang-kenangan pada pihak mitra dalam hal ini SMKN 6 Tangerang Selatan, juga penyerahan doorprize untuk peserta kegiatan.

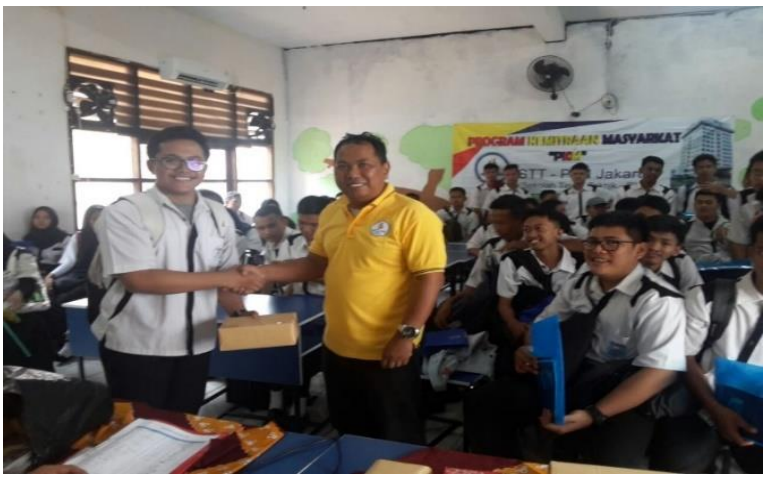

Gambar 12. Penyerahan Doorprize

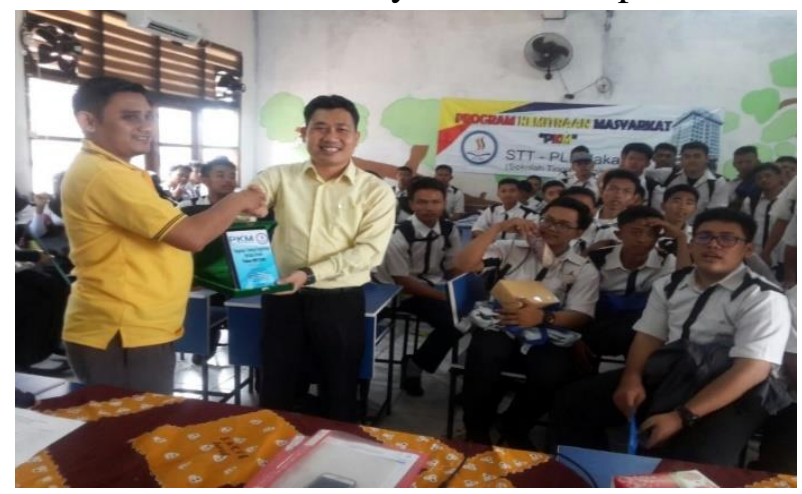

Gambar 13. Penyerahan Kenangan-kengan Pada Pihak Sekolah

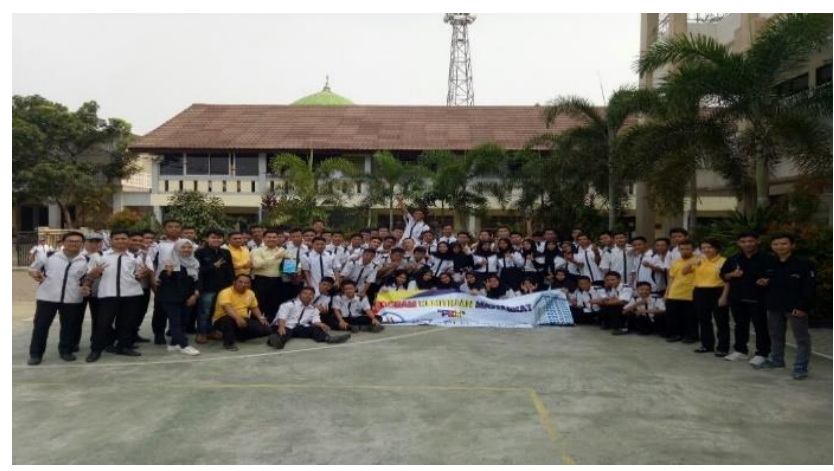

Gambar 14. Foto Bersama Mitra PKM

Kegiatan PKM berupa Pengenalan Teknologi Pengontrolan Berbasis Arduino di Sekolah Menengah Kejuruan berhasil dilakukan dan menghasilkan luaran sebagai berikut:

1. Peserta mampu memahami dan membuat pemrograman tentang teknologi pengontrolan elektronika berbasis Arduino. 
2. Peserta mampu menyimulasikan program sederhana menggunakan Arduino, dibuktikan dengan beberapa siswa/ siswi yang mampu membuat program dan mempresentasikan di depan kelas secara antusias.

3. Peserta memahami bagaimana proses otomatisasi pada sistem yang dibuat dengan menggunakan mikrokontroller platform arduino sebagai alat pengontrol beserta pemogramannya.

4. Pelaksanaan salah satu Tridarma perguruan tinggi yaitu pengabdian pada masyarakat yang berguna bagi peningkatan kompetensi siswa SMK.

\section{B. Kendala Pada Saat Kegiatan}

Terdapat kendala yang dihadapi pada saat kegiatan PKM. Kendala dan solusi pada saat kegiatan PKM tersebut antara lain:

1. Tanggal pelaksanaan

Kendala pertama pelaksanaan PKM adalah perihal penentuan tanggal pelaksanaan. Tanggal pelaksanaan ditentukan oleh kedua belah pihak, yaitu oleh pihak STT-PLN selaku pemberi materi pelatihan dan pihak SMKN 6 Tangerang Selatan selaku sasaran dan peserta pelatihan. Tanggal pelaksanaan ditetapkan sebelum bulan Juli 2018 karena pada bulan Mei sekolah telah disibukkan dengan ujian nasional serta ujian akhir semester, juga libur sekolah dan lebaran bulan Juni 2018. Setelah dilakukan proses musyawarah, diperoleh kesepakatan bahwa tanggal pelaksanaan PKM berupa kegiatan pelatihan adalah tanggal 26-27 Juli 2018.

2. Laptop

Kegiatan pelatihan ini memerlukan laptop sebagai penunjang pelatihan. Laptop diperlukan untuk menjalankan software yang dihubungkan pada tool kit arduino. Sekolah tidak memiliki cukup komputer untuk siswa, sehingga siswa diminta untuk membawa laptop pribadi ke sekolah. Ada sebagian siswa yang tidak membawa laptop padahal kegiatan pelatihan hari pertama adalah menginstal software. Solusi untuk kendala ini adalah siswa yang tidak membawa laptop diminta untuk bergabung dengan siswa yang membawa laptop.

3. Kehadiran Peserta

Masalah yang dihadapi selanjutnya adalah masalah jumlah peserta. Pelatihan ini pihak sekolah meminta untuk diadakan dengan jumlah peserta 4 kelas, kelas XI 2 kelas dan kelas XII 2 Kelas dengan jumlah masing-masing perkelas 40 siswa. Permasalahan jumlah peserta kegiatan akhirnya menemui solusi, dikarenakan tempat penyelenggara (sekolah) masih terkendala ruangan serta tidak adanya aula sehingga diputuskan hanya kelas XII untuk 2 kelas, dengan jumlah siswa masing-masing perkelas 40 siswa/ siswi. Namun pada pelaksanaan ada peserta yang izin telah disampaikan oleh pihak sekolah sehingga jumlah peserta rata-rata perkelas 37 Siswa. 


\section{Suasana Kelas}

Kegiatan pengenalan dan pelatihan ini diberikan kepada siswa/siswi SMK. Pada awal kegiatan peserta merasa asing dengan teknologi ini, mereka hanya tahu aplikasi yang digunakan tanpa tahu teknologi apa yang digunakan. Setelah dijelaskan siswa/ siswi antusias dengan pemaparan materi, demo alat, serta simulasi yang dilakukan, juga pemutaran video dan diskusi yang dilakukan setelahnya.

\section{KESIMPULAN}

Kesimpulan dari pelaksanaan program kemitraan masyarakat yang diselenggarakan di SMKN 6 Tangerang selatan ini adalah sebagai berikut.

1. Meningkatnya pengetahuan dan pemahaman guru dan siswa-siswi SMK Negeri 6 Tangerang Selatan tentang Sistem Pengontrolan elektronis berbasis Mikrokontroler.

2. Meningkatnya keinginan siswa untuk mempelajari sistem otomatisasi pengontrolan elektronis berbasis mikrokontroller

3. Siswa dan guru di SMKN 6 Tangerang Selatan memiliki pengetahuan dan pemahaman guru dan siswa tentang penggunaannya arduino beserta pemogramannya.

4. Meningkatnya pengetahuan guru dan siswa tentang aplikasi sistem kendali sederhana.

5. Pelatihan atau kegiatan ini sangat perlu untuk dikembangkan agar kegiatan berikutnya menjadi lebih baik dan berguna didalam peningkatan SDM yang menjadi bagian penting dalam mewujudkan "transferable skills" yang telah dipelajari.

\section{SARAN}

Dalam penulisan jurnal Program Kemitraan Masyarakat yang diselenggarakan di SMKN 6 Tangerang Selatan ini masih terdapat banyak kelemahan, adapun saran yang kami sampaikan pada pihak-pihak terkait adalah sebagai berikut.

1. Perlu dilakukan kerjasama antara pihak perguruan tinggi, pemerintah daerah dan masyarakat untuk dapat menyebar luaskan ilmu pengetahuan kepada masyarakat.

2. Perlu di buat suatu daerah binaan (sekolah, masyarakat) oleh perguruan tinggi khususnya Sekolah Tinggi Teknik PLN agar tujuan dari pengabdian dan kemitraan kepada masyakat ini dapat terarah dan tercapai.

\section{UCAPAN TERIMA KASIH}

Terimakasih disampaikan kepada mitra dalam hal ini SMKN 6 Tangerang Selatan yang menyediakan waktu dan tempat kegiatan, STT PLN melalui LP3M dan Program Studi Teknik Elektro yang mendukung serta mendanai kegiatan PKM. Kedepan semoga kegiatan semacam ini dapat terus dilanjutkan dan ditingkatkan demi terciptanya masyarakat yang sejahtera, adil dan makmur dengan memanfaatkan teknologi. 


\section{DAFTAR PUSTAKA}

[1] Kadir, Abdul., 2013, Panduan Praktis Mempelajari Aplikasi Mikrokontroller dan Pemrogramannya menggunakan Arduino, Andipublisher, Yogyakarta

[2] Damiri, 2012, Implementation Project Based Learning on Local Area Network Training, International Journal of Basic and Applied Science,

[3] Smith. Alan G., 2011, Introduction to Arduino - A piece of cake, Cambridge University Press, New York

[4] Durfee, W., 2011, Arduino Microcontroller Guide, University of Minnesota, diakses dari : http://www.me.umn.edu/courses/me2011/arduino/arduinoGuide.pdf

[5] Ladyada, 2013, Arduino Tips, Tricks, and Techniques, Adafruit learning system, Autoedición, Madrid. 